\title{
Hydrological simulations driven by RCM climate scenarios at basin scale in the Po River, Italy
}

\author{
R. VEZZOLI ${ }^{1}$, M. DEL LONGO ${ }^{2}$, P. MERCOGLIANO ${ }^{1,3}$, \\ M. MONTESARCHIO ${ }^{1,3}$, S. PECORA ${ }^{2}$, F. TONELLI ${ }^{2} \&$ A. L. ZOLLO ${ }^{1}$ \\ 1 Impacts on Soil and Coasts Division (ISC), Centro Euro-Mediterraneo sui Cambiamenti Climatici (CMCC), via \\ Maiorise, I-81043, Capua (CE), Italy \\ renata.vezzoli@cmcc.it \\ 2 ARPA Emilia-Romagna, HydroMeteoClimate Service, Hydrology Area (ARPA SIMC), via G. Garibaldi 75, I-43121, \\ Parma, Italy \\ 3 Italy Meteo System and Instrumentation Laboratory, Italian Aerospace Research Center (CIRA), via Maiorise, \\ I-81043, Capua (CE), Italy
}

\begin{abstract}
River discharges are the main expression of the hydrological cycle and are the results of climate natural variability. The signal of climate changes occurrence raises the question of how it will impact on river flows and on their extreme manifestations: floods and droughts. This question can be addressed through numerical simulations spanning from the past (1971) to future (2100) under different climate change scenarios. This work addresses the capability of a modelling chain to reproduce the observed discharge of the Po River over the period 1971-2000. The modelling chain includes climate and hydrological/hydraulic models and its performance is evaluated through indices based on the flow duration curve. The climate datasets used for the 1971-2000 period are (a) a high resolution observed climate dataset, and COSMOCLM regional climate model outputs with (b) perfect boundary condition, ERA40 Reanalysis, and (c) suboptimal boundary conditions provided by the global climate model CMCC-CM. The aim of the different simulations is to evaluate how the uncertainties introduced by the choice of the regional and/or global climate models propagate in the simulated discharges. This point is relevant to interpret the results of the simulated discharges when scenarios for the future are considered. The hydrological/hydraulic components are simulated through a physically-based distributed model (TOPKAPI) and a water balance model at the basin scale (RIBASIM). The aim of these first simulations is to quantify the uncertainties introduced by each component of the modelling chain and their propagation. Estimation of the overall uncertainty is relevant to correctly understand the future river flow regimes. The results show how bias correction algorithms can help in reducing the overall uncertainty associated to the different stages of the modelling chain.
\end{abstract}

Key words climate change; regional climate model; hydrological modelling; flow duration curve; bias correction

\section{INTRODUCTION}

The majority of the climate models agree in expecting, in the Mediterranean area, an increase in the frequency of extreme precipitation events while intensity will be almost unchanged, and, on average, a decrease in the total precipitation (Christensen et al. 2007). The foreseen partitioning of precipitation enhances the possibility of an alternation of long dry periods and short extremely wet ones, causing an increase in the hydrological vulnerability of the region (Blenkinsop and Fowler 2007). The effects of climate change on floods and droughts have been recently addressed by Christensen et al. (2004), Fowler and Kilsby (2004), Blenkinsop and Fowler (2007), Hirabashi et al. (2008), te Linde et al. (2010, 2011), Seidou et al. (2012a,b), and at European level (for floods) by Directive 2007/60/EC of the European Parliament and Council. The European Directive deals with the assessment and management of flood risk, and the reduction of its adverse consequences, recognizing the role of both anthropogenic activities and climate change forcing. In Italy, the vulnerability to variation in the precipitation partitioning is emphasized by the presence of small catchments that tend to quickly overflow in response to heavy rainfall, even of short duration, and by the high urbanization rate of areas close to the rivers. To investigate the impacts of climate change on river flow regimes, we set up a climate/hydrological modelling chain that provides daily discharges of the Po River and its tributaries. The case study was selected because of the Po River's national relevance, dimensions, availability of observations, and the increased severity of floods and droughts events experienced in the last decades (Zanchettin et al. 2008). In addition, a calibrated and validated hydrological/hydraulic chain is available at the Hydro-Meteo-Climate Service of the Regional Agency for Prevention and Environment (ARPA SIMC) of the EmiliaRomagna Region in North Italy (Casicci et al. 2006). Here, the capability of the modelling chain to 
reproduce Po River discharge for 1971-2000 is analysed together with the evaluation of its performance.

\section{MODELS AND METHODOLOGY}

The aim of these climate/hydrological simulations is to investigate the impacts of climate change on extreme discharges and the adaptability to climate change of the Po River. The simulations are performed through a climate/hydrological modelling chain composed in a cascade by: (a) a module for the climate, i.e. precipitation and 2-m temperature, and (b) a hydrological/hydraulic module to simulate the climate impacts at the soil. The hydrological/hydraulic part of the modelling chain is common to all the simulations and it is composed of TOPKAPI (TOPographic Kinematic Approximation and Integration), a physically-based and spatially-distributed hydrological model (Liu and Todini 2002) used to obtain the runoff that is the input to RIBASIM (RIver BAsin SIMulation), a water balance model at basin scale to simulate the average daily discharge at different sections of the river network (Delft Hydraulics 2006). The simulations over the period 1971-2000 are driven by different climate datasets: (a) high resolution observed data; precipitation was provided by ARPA SIMC on the basis of Hydrological Yearbooks while temperature is based on EOBS dataset (Haylock et al. 2008), additional temperature information were available for the period 1991-2010 from ARPA SIMC; precipitation and temperature obtained from the regional climate model (RCM) COSMO-CLM (Rockel et al. 2008) driven by (b) perfect boundary conditions given by the ERA40 Reanalysis (Uppala et al. 2006) and (c) suboptimal boundary conditions from the global climate model (GCM) CMCC-CM (Scoccimarro et al. 2011). The nominal resolution of the ERA40 Reanalysis is $1.125^{\circ}$ (about $128 \mathrm{~km}$ ) and $0.75^{\circ}$ (about $85 \mathrm{~km}$ ) for CMCC-CM; both are dynamically downscaled to a nominal resolution of $0.0715^{\circ}$ (about $8 \mathrm{~km}$ ) through COSMO-CLM that is more suitable for hydrological studies. A detailed description of the regional climate model COSMO-CLM and its validation when driven by ERA40 Reanalysis or CMCC-CM, is available in Montesarchio et al. (2012) and Zollo et al. (2012). The first simulation, driven by climate observations, is used as the reference simulation; the second aims to evaluate how the uncertainties introduced by the RCM propagate in the simulated discharges; and the last is designed to evaluate the joint effects of the GCM and the RCM on the discharges. This point is relevant for the interpretation of climate change impacts when future scenarios are considered. The climate change impacts on the period 2001-2100 will be simulated under the IPCC Representative Concentration Pathways (RCP) 4.5 and 8.5 (Meinshausen et al. 2011). Preliminary results based on the RCP4.5 scenario over the period 2012-2040 will be briefly illustrated in the "Case Study" section. The capability of the modelling chain to reproduce the frequency of (extreme) discharges is evaluated through the flow duration curve (FDC) and five indices based on it. The FDC provides the average period of exceedence of a given discharge that is proportional to the discharge exceeding probability $(1-F)$ where $F$ is the cumulative distribution function. The five indices were introduced by Yilmaz et al. (2008) and applied with some minor modifications by Herbst et al. (2009) and Casper et al. (2012). The indices are defined as follows:

(a) RQ1 is the bias in the expected discharge, $E[Q]$ :

$$
\mathrm{RQ} 1=\frac{E[Q]}{E\left[Q_{\mathrm{Ref}}\right]}-1
$$

(b) RQ2 is the bias in the median value $Q_{50}$ :

$$
\mathrm{RQ} 2=\frac{Q_{50}}{Q_{\mathrm{Ref}, 50}}-1
$$

(c) RQ3 is related to the slope of the mid-segment that is indicative of the average rate of change of daily discharge; $Q_{20}$ and $Q_{70}$ are the discharges with an exceedence probability $(1-F)$ of $20 \%$ and $70 \%$, respectively: 


$$
\text { RQ3 }=\frac{\log _{10}\left(Q_{20}\right)-\log _{10}\left(Q_{70}\right)}{\log _{10}\left(Q_{\text {Ref }, 20}\right)-\log _{10}\left(Q_{\text {Ref }, 70}\right)}-1
$$

(d) RQ4 is the bias in high-segment volumes and is used to compare the highest discharges, i.e. discharges with an exceeding probability less than 0.02 :

$$
\mathrm{RQ} 4=\frac{\int_{p=0}^{0.02} Q(p) \mathrm{dp}}{\int_{p=0}^{0.02} Q_{\text {Ref }}(p) \mathrm{dp}}-1
$$

(e) RQ5 is the bias in long-term baseflow (low discharges); i.e. it compares the volume of discharge with an exceeding probability greater than 0.7 :

$$
\mathrm{RQ} 5=\frac{\int_{p=0.7}^{1} \log _{10} Q(p)-\log _{10} Q(p=1) \mathrm{dp}}{\int_{p=0.7}^{1} \log _{10} Q_{\text {Ref }}(p)-\log _{10} Q_{\text {Ref }}(p=1) \mathrm{dp}}-1
$$

To remove uncertainties introduced by the RCM and/or the GCM on precipitation and temperature different techniques are available (e.g. Turco et al. 2013). However, in this work the simulated discharges are corrected directly at monthly scale through the following relationship:

$$
Q^{*}=F_{\mathrm{Ref}}^{-1}(F(Q))
$$

where $F(Q)$ is the distribution function of the simulated discharge, and $F_{\text {Ref }}{ }^{-1}$ is the inverse of distribution function calculated for the reference simulation, i.e. the one driven by the observed climate; the Hazen plotting position was assumed as the distribution function:

$$
F(Q)=\frac{i-0.5}{N}
$$

where $i$ is the average rank of $Q$ and $N$ is the sample size. The quantile correction allows removal of most of the overall calibration uncertainties related to the components of the modelling chain acting on the value of the discharge for any given frequency of occurrence. Because the frequency of occurrence prescribed by the simulation is maintained it is possible to extrapolate considerations of changes in discharge frequency between future and reference periods. For the case presented here, the quantile correction was calibrated month by month over the period 1972-1990 and validated over the period 1991-2000. The year 1971 is neglected because it was the spin-up year in all the simulations.

\section{CASE STUDY}

The Po River is the longest in Italy, with a length of $652 \mathrm{~km}$ from its source in the Cottian Alps (at Pian del Re) to its mouth in the Adriatic Sea (north of Ravenna) and is the largest Italian river with an average discharge of $1540 \mathrm{~m}^{3} / \mathrm{s}$. The Po River basin is the widest in Italy and covers an area of about $71000 \mathrm{~km}^{2}$ in Italy, and about $3000 \mathrm{~km}^{2}$ in Switzerland and France (Fig. 1). In the context of Italian Law 183/1989, the Po basin is classified as of national importance. The orography of the basin is quite complex as it is bounded by the Alps and Apennines with the Po valley between.

Figure 2(a) and (b) provides a comparison between the monthly average areal precipitation and discharges, respectively, for the different climate datasets used over the period 1972-2000. The comparison shows that the precipitation is overestimated from December to July and underestimated from September to November using either ERA40 Reanalysis or CMCC-CM as boundary condition to COSMO-CLM, Fig. 2(a), this is reflected in the discharge seasonality, Fig. 2(b). The overestimation of precipitation in spring with respect to observed climate causes a shift in the discharge maximum from May to June, while the underestimation in autumn results in a reduction of the October peaks. The comparison among the FDCs shows that the simulations tend to overestimate the reference quantiles, Fig. 2(c). The RQ indices, computed according to equations (1)-(5), show that the mean and median discharges are overestimated; in particular the RQ1 index assumes values of 0.13 (simulation with ERA40 Reanalysis as boundary conditions) 


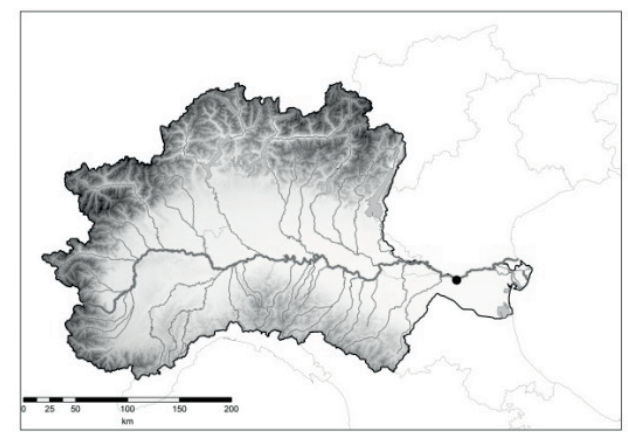

Fig. 1 Po River and its main tributaries; the dot indicates the river closure section of Pontelagoscuro.

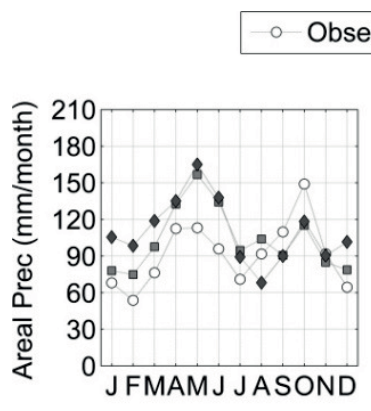

(a)

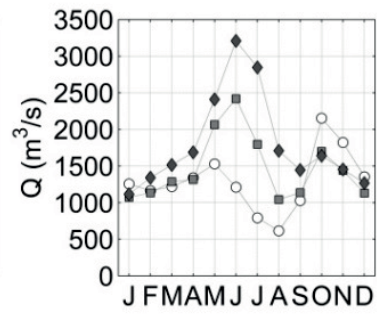

(b)
- CMCC-CM

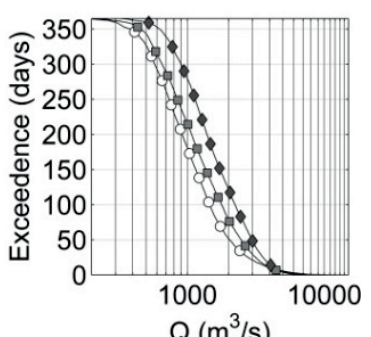

(c)

Fig. 2 Monthly average (a) areal precipitation and (b) discharge at Pontelagoscuro and (c) FDCs. In panel (c) only some of the points are indicated with the symbols. The simulations are labelled according to the climate data used to force them: observations, COSMO-CLM driven by ERA40 Reanalysis or COSMO-CLM driven by CMCC-CM.

Table 1 Values of the RQ indices computed in the calibration (1972-1990), validation (1991-2000) and for the whole simulation period (1972-2000) for original discharge time series with respect to the simulation driven by the observed climate over the same periods. Values in brackets refer to corrected simulations. Simulations are identified by the climate boundary condition used.

\begin{tabular}{|c|c|c|c|c|c|c|}
\hline Period & $1972-2000$ & & $1972-1990$ & & $1991-2000$ & \\
\hline $\begin{array}{l}\text { Climate boundary } \\
\text { conditions }\end{array}$ & $\begin{array}{l}\text { ERA40 } \\
\text { Reanalysis }\end{array}$ & $\mathrm{CMCC}-\mathrm{CM}$ & $\begin{array}{l}\text { ERA40 } \\
\text { Reanalysis }\end{array}$ & $\mathrm{CMCC}-\mathrm{CM}$ & $\begin{array}{l}\text { ERA40 } \\
\text { Reanalysis }\end{array}$ & CMCC-CM \\
\hline RQ1 & $0.13(-0.05)$ & $0.40(-0.04)$ & $0.22(-0.01)$ & $0.46(-0.01)$ & $-0.03(-0.15)$ & $0.29(-0.12)$ \\
\hline RQ2 & $0.17(-0.03)$ & $0.51(-0.01)$ & $0.24(0.00)$ & $0.53(0.00)$ & $0.05(-0.13)$ & $0.43(-0.05)$ \\
\hline RQ3 & $0.08(0.00)$ & $-0.01(-0.02)$ & $0.07(-0.01)$ & $-0.04(-0.01)$ & $0.06(-0.02)$ & $-0.01(-0.05)$ \\
\hline RQ4 & $-0.16(-0.14)$ & $-0.10(-0.13)$ & $-0.04(-0.04)$ & $0.02(-0.04)$ & $-0.36(-0.31)$ & $-0.30(-0.29)$ \\
\hline RQ5 & $0.19(-0.41)$ & $-0.09(-0.36)$ & $0.88(0.00)$ & $0.42(0.00)$ & $-0.04(-0.51)$ & $-0.18(-0.34)$ \\
\hline
\end{tabular}

and 0.40 (CMCC-CM as boundary condition); RQ2 is equal to 0.17 and 0.51 , respectively; the slope is well reproduced (RQ3 $=0.08$ and -0.01 , respectively); while the volumes associated with the highest discharges are underestimated (RQ4 $=-0.16$ and -0.10 , respectively); and the volume relative to the lowest discharges is overestimated (underestimated) using ERA40 Re-analysis $(\mathrm{CMCC}-\mathrm{CM})$ as boundary conditions, RQ5 $=0.19(-0.09)$, Table 1 . The quantile correction illustrated in equation (6) is applied at monthly scale using 1972-1990 as the calibration period and 1991-2000 for validation, obtaining a correct reproduction of the monthly average discharge. Figures 3(a) and (b) report the comparison of the FDCs in the calibration and validation periods, respectively. The FDCs of the corrected simulations are close to that of the reference simulation in the calibration period, while in the validation period, there are differences in the extreme discharges, see Table 1 and Fig. 3. The difficulty in reproducing the highest discharges in the validation period is mainly due to: (a) the choice of the Hazen plotting position as the probability distribution function that is not able to simulate values outside its calibration range, and (b) the presence of higher maxima in the validation period relative to the calibration one. However, Table 


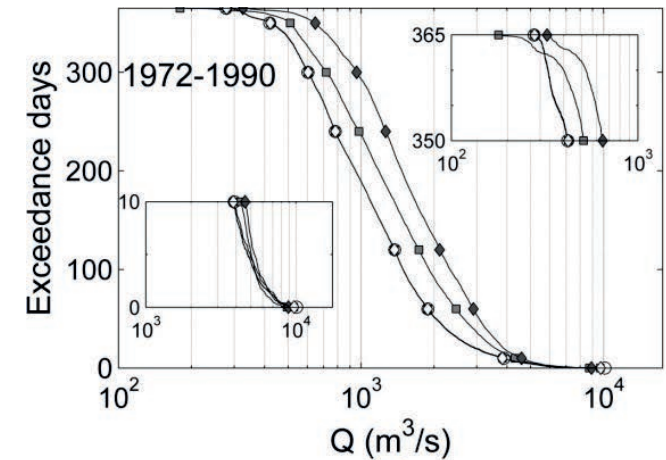

(a)

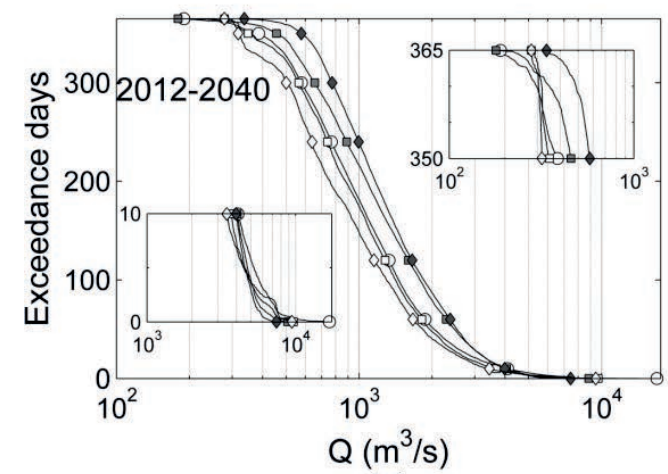

(c)

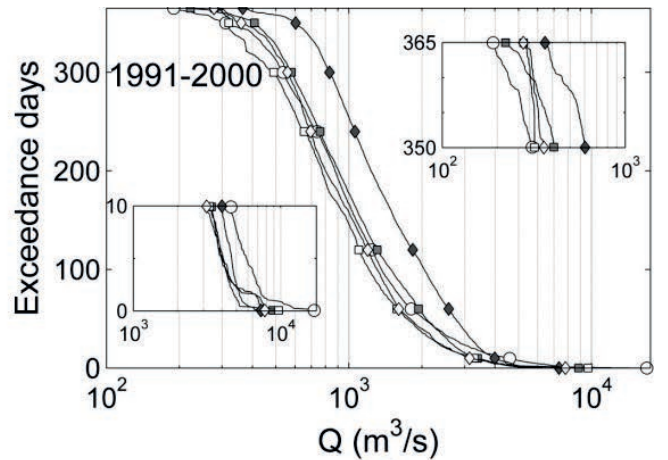

(b)

Fig. 3 Comparison among FDCs in: (a) calibration, (b) validation and (c) future periods. Original and corrected (indicated with * in the legend) FDCs are reported for comparison. In panel (c), the future FDCs are compared with the FDC of the reference simulation over the period 1972-2000. In each panel, the insets are a zoom on highest (left) and lowest (right) discharges. The symbols are not representative of all points used to build the FDCs. The simulations are labelled according to the climate data used to force them: observations, COSMO-CLM driven by ERA40 Reanalysis or COSMO-CLM driven by CMCCCM.

1 and Fig. 3 show how the application of equation (6) reduces the differences among the FDCs and thus the uncertainties introduced with the choice of the RCM and the GMC. The relevance of the uncertainties introduced by the coupled GCM/RCM is of particular interest to evaluate the impacts of the climate changes, e.g. Fig. 3(c) shows a comparison among the FDCs of the reference simulation over the period 1972-2000 and discharges from a simulation driven by COSMO-CLM with CMCC-CM as boundary condition for 2012-2040, before and after the application of the correction in probability. The IPCC scenario considered is the RCP4.5. The correction in probability completely changes the simulation results and their interpretation, i.e. where the original simulation sees an increase in the mean and median discharge the corrected one expects a reduction (RQ1 varies from 0.19 to -0.13 and RQ2 from 0.26 to -0.16 ), the slope increases: RQ3 goes from -0.01 to 0.09 , the volume of maximum discharges decreases, with respect to the reference period, in both cases RQ4 goes from -0.20 to -0.10 , and minimum discharges are, on average more severe but their variability reduces from $337-935 \mathrm{~m}^{3} / \mathrm{s}$ for the incorrect simulation to $278-604 \mathrm{~m}^{3} / \mathrm{s}$ for the corrected one and RQ5 changes from -0.24 to -0.54 .

\section{CONCLUSIONS}

The study of climate change and its impact on river discharge is based on numerical modelling. However, the results of numerical simulations are affected by uncertainties introduced by the assumptions associated with each step of the simulation process itself. Here, a procedure to quantify the uncertainty introduced by the choice of the RCM and/or GCM on river discharge through the use of the flow duration curve and indices based on it is described. We also show how a simple correction in probability is able to remove most of the differences in the simulation 
outputs over a reference period. The relevance of the correction is more evident when applied to future scenarios. For the case of the Po River at Pontelagoscuro, the application of the correction in probability completely changes the impacts of the climate changes impacts on the flow duration curve for the 2012-2040 period under RCP4.5. The capability of the correction procedure to change the sign of the simulation results should be taken into account before drawing conclusions on climate change impacts due to the overall uncertainties affecting the simulation results.

Acknowledgements The research leading to these results has received funding from the Italian Ministry of Education, University and Research and the Italian Ministry of Environment, Land and Sea under the GEMINA and Next Data projects.

\section{REFERENCES}

Blenkinsop, S. and Fowler, H.J. (2007) Changes in European drought characteristics projected by the PRUDENCE regional climate models. Int. J. Climatol. 27(12), 1595-2610.

Casicci, L., Ioiò, C. and Pecora S. (2006) An operational system for the Po flood forecasting in Italy. In: 7th International Conference on Hydroinformatics, HIC, Nice, France.

Casper, M. C., et al. (2012) Analysis of projected hydrological behavior of catchments based on signature indices. Hydrol. Earth Syst. Sc., 16(2), 409-421.

Christensen, J. H., et al. (2007) Climate Change 2007: The Physical Science Basis. Contribution of Working Group I to the Fourth Assessment Report of the Intergovernmental Panel on Climate Change, chapter Regional Climate Projections. Cambridge University Press.

Christensen, N. S., et al. (2004) The effects of climate change on the hydrology and water resources of the Colorado river basin. Climatic Change 62(1-3), 337-363.

Delft Hydraulics (2006) River Basin Planning and Management Simulation Program. In: Proceedings of the iEMSs Third Biennial Meeting: "Summit on Environmental Modelling and Software", (ed. by A. Voinov, A. J. Jakeman and A. E. Rizzoli), International Environmental Modelling and Software Society.

Fowler, H. J. and Kilsby, C. G. (2004) Future increases in UK water resources projected by a regional climate model. In: Hydrology Science and Practice for the 21st century (ed. by B. Webb et al.) 15-21, British Hydrological Society).

Haylock, M. R., et al. (2008) A European daily high-resolution gridded data set of surface temperature and precipitation for 1950-2006. J. Geophys. Res., 113(D20119), doi:10.1029/2008.JD10201.

Herbst, M., Gupta, H. V., and Casper, M. C. (2009) Mapping model behaviour using self-organizing maps. Hydrol. Earth Syst. Sci., 13, 395-409.

Hirabashi, Y., et al. (2008) Global projections of changing risks of floods and droughts in a changing climate. Hydrological Sciences Journal 53(4), 754-772.

Liu, Z. and Todini, E. (2002) Towards a comprehensive physically-based rainfall-runoff model. Hydrol. Earth Syst. Sc. 6(5), 859-881.

Meinshausen, M., et al. (2011) The RCP Greenhouse Gas Concentrations and their Extension from 1765 to 2300 . Climatic Change, 109(1-2), 213-241

Montesarchio, M., et al. (2012) Performance evaluation of a regional climate simulation with COSMO-CLM in the Alpine space. CMCC Research Paper - RP00137.

Rockel, B., Will, A. and Hense, A. (2008) The regional climate model COSMO-CLM (CCLM). Meteorol. Z., 17(4), 347-348.

Scoccimarro, E., et al. (2011) Effects of tropical cyclones on ocean heat transport in a high resolution coupled general circulation model. J. Climate 24, 4368-4384.

Seidou, O., Ramsay, A. and Nistor, I. (2012a) Climate change impacts on extreme floods I: combining imperfect deterministic simulations and nonstationary frequency analysis. Nat. Hazard 61, 647-657.

Seidou, O., Ramsay, A., and Nistor, I. (2012b) Climate change impacts on extreme floods II: improving flood future peaks simulation using nonstationary frequency analysis. Nat. Hazard 60, 715-726.

te Linde, A. H., et al. (2010) Simulating low probability peak discharges for the Rhine basin using resampled climate modeling data. Water Resour. Res. 46, W04512.

te Linde, A.H., et al. (2011). Future flood risk estimates along the river Rhine. NHESS 11, 459-473.

Turco, M. et al. (2013) Daily precipitation statistics over the Po Basin: observation and post-processed RCM results. In: Climate Change and its Implications on Ecosystem and Society, Proceedings of SISC First Annual Conference, Lecce 2013, 222-234, SISC.

Uppala, S. M., et al. (2006) The ERA40 Re-analysis. Quart. J. Roy. Meteor. Soc. 612, 2961-3012.

Yilmaz, K. K., Gupta, H. V. and Wagener, T. (2008) A process based diagnostic approach to model evaluation: Application to the NWS distributed hydrologic model. Water Resour. Res. 44(9), W09417.

Zanchettin, D., Traverso, P. and Tomasino, M. (2008) Po River discharge: a preliminary analysis of a 200 year time series. Climatic Change 89, 411-433.

Zollo A. L., et al. (2012) Assessment of COSMO-CLM performances in simulating the past climate of Italy. CMCC Research Paper-RP0145. 